\title{
PI and Fuzzy Logic Controller Based 3-Phase 4-Wire Shunt Active Filters for the Mitigation of Current Harmonics with the $\mathrm{I}_{d}-\mathrm{I}_{q}$ Control Strategy
}

\author{
Suresh Mikkili ${ }^{\dagger}$ and Anup Kumar Panda* \\ $\dagger *$ Dept. of Electrical Engineering, National Institute of Technology Rourkela, Rourkela, India
}

\begin{abstract}
Commencing with incandescent light bulbs, every load today creates harmonics. Unfortunately, these loads vary with respect to their amount of harmonic content and their response to problems caused by harmonics. The prevalent difficulties with harmonics are voltage and current waveform distortions. In addition, Electronic equipment like computers, battery chargers, electronic ballasts, variable frequency drives, and switching mode power supplies generate perilous amounts of harmonics. Issues related to harmonics are of a greater concern to engineers and building designers because they do more than just distort voltage waveforms, they can overheat the building wiring, cause nuisance tripping, overheat transformer units, and cause random end-user equipment failures. Thus power quality is becoming more and more serious with each passing day. As a result, active power filters (APFs) have gained a lot of attention due to their excellent harmonic compensation. However, the performance of the active filters seems to have contradictions with different control techniques. The main objective of this paper is to analyze shunt active filters with fuzzy and pi controllers. To carry out this analysis, active and reactive current methods $\left(i_{d}-i_{q}\right)$ are considered. Extensive simulations were carried out. The simulations were performed under balance, unbalanced and non sinusoidal conditions. The results validate the dynamic behavior of fuzzy logic controllers over PI controllers.
\end{abstract}

Key Words: Fuzzy logic controller, Harmonic compensation, $\mathrm{I}_{d}-\mathrm{I}_{q}$ control strategy, PI controller, Shunt Active power filter

\section{INTRODUCTION}

In recent years power quality [1] has become an important and growing problem due to the proliferation of nonlinear loads such as power electronic converters in typical power distribution systems. Particularly, voltage harmonics and power distribution equipment problems are the result of current harmonics [2] produced by nonlinear loads.

Eminent issues always arises in three-phase four-wire systems. It is well-known the that zero line may be overheated or causes a fire as a result of excessive harmonic current [3] going through the zero line three times or times that of three. Thus a perfect compensator is necessary to avoid the negative consequences of harmonics. Though several control techniques and strategies have been developed they still have contradictions with the performance of filters. These issues became the primary motivation for this paper.

In the $i_{d}-i_{q}$ method from [4] the angle ' $\theta$ ' is calculated directly from the main voltages which enables the method to be frequency independent. As a result, a large number of syn-

Manuscript received Nov. 15, 2010; revised Sep. 8, 2011

Recommended for publication by Associate Editor Kyo-Beum Lee.

$\dagger$ Corresponding Author: msuresh.ee@ gmail.com

Tel: +91-78797867, Fax: +91-661-2462999, N.I.T Rourkela

${ }^{*}$ Dept. of Electrical Engineering, National Institute of Technology Rourkela, India chronization problems with un-balanced and non-sinusoidal voltages are avoided.

The PI controller in [5] requires precise linear mathematical models, which are difficult to obtain and may not give satisfactory performance under parameter variations, load disturbances, etc. Recently, fuzzy logic controllers have received a great deal of attention in regards to their application to APFs. The advantages of fuzzy controllers over conventional controllers are that they do not require an accurate mathematical model, can work with imprecise inputs, can handle nonlinearity, and are more robust than conventional controllers. The Mamdani type of fuzzy controller from [6], used for the control of an APF, gives better results when compared with PI controllers, but it has the drawback of a larger number of fuzzy sets and 49 rules.

This paper focuses mainly on two controllers i.e., fuzzy and pi. In addition, a filter was developed with the instantaneous active and reactive current $\left(i_{d}-i_{q}\right)$ method. This was then used to analyse the performance of the filter under different main voltages. This shows that the fuzzy controllers exhibit some superior performance over the PI controllers. To validate the current observations, extensive simulations were carried out and adequate results were obtained. 


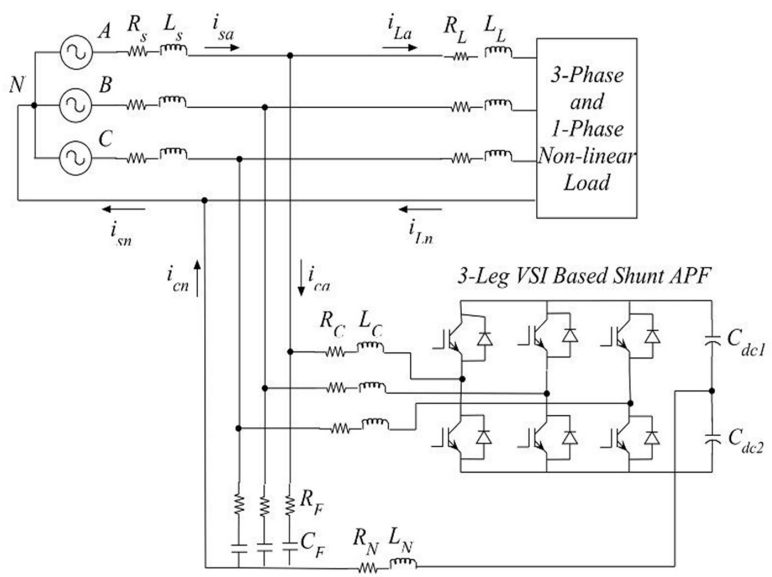

Fig. 1. Three-leg split capacitor Shunt APF with Non-linear load.

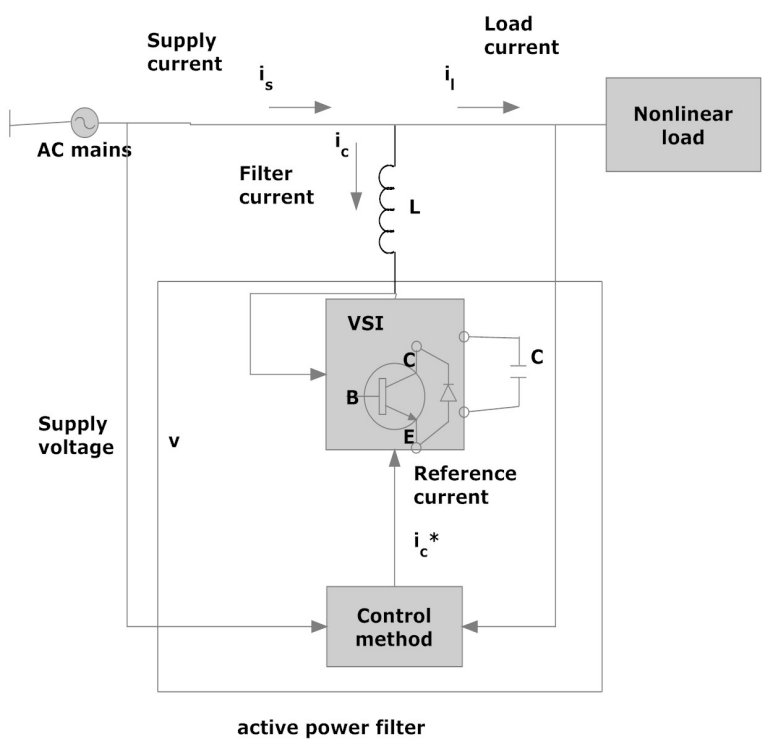

Fig. 2. Compensation Characteristics of a SHAF.

\section{Shunt Active Filter Configuration}

The active filter currents are achieved from the instantaneous active and reactive powers [7], $p$ and $q$, of a non-linear load. Fig. 1 shows a three-leg structure with a neutral conductor being connected at the midpoint of a dc-link capacitor.

The three-leg six-switch split-capacitor configuration of a shunt APF suffers from several shortcomings.

(a) The control circuit is somewhat complex.

(b) The voltages of the two capacitors of a split-capacitor need to be properly balanced.

(c) Large dc-link capacitors are required.

\section{A. Compensation principle}

An active power filter is controlled to draw/supply a compensating current if from/to the load to cancel out the current harmonics on the AC side and a reactive power flow from/to the source, there by making the source current in phase with the source voltage. Fig. 2 shows the basic compensation principle of an active power filter.

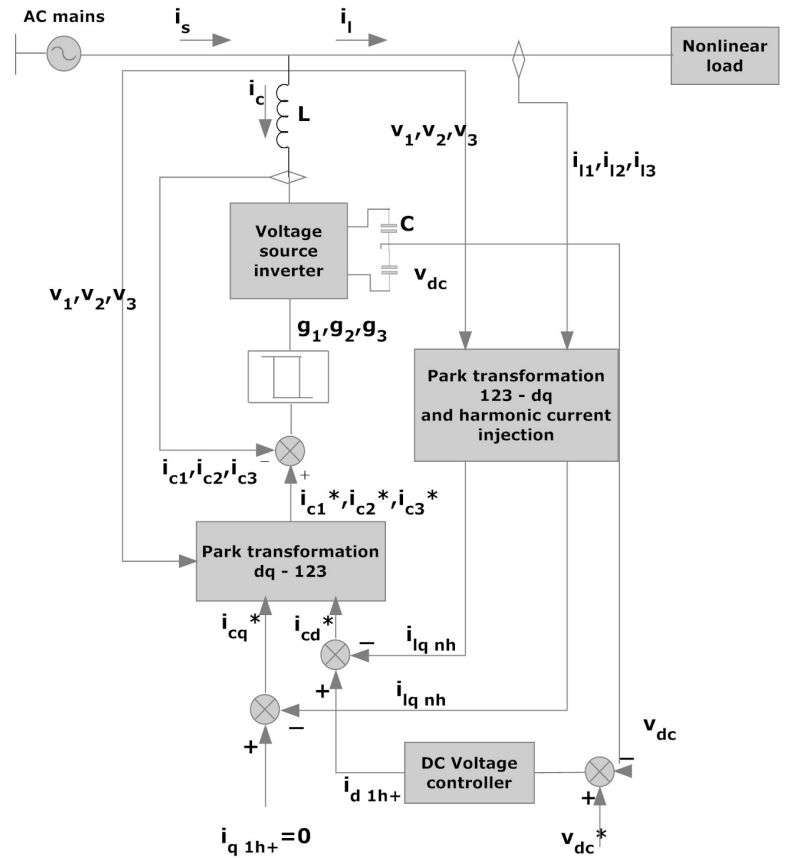

Fig. 3. Control method for Shunt current compensation based on $\mathrm{I}_{d}-\mathrm{I}_{q}$ theory.

\section{Instantaneous Active And Reactive CurRent $\left(\mathrm{I}_{d}-\mathrm{I}_{q}\right)$ THEORY}

In this method [8], only the currents magnitudes are transformed and the $\mathrm{p}-\mathrm{q}$ formulation is only performed on the instantaneous active $\dot{i}_{d}$ and instantaneous reactive $\dot{i}_{q}$ components. If the $d$ axis has the same direction as the voltage space vector $\bar{v}$, then the zero-sequence component of the current remains invariant. Therefore, the $\mathrm{i}_{d}-\mathrm{i}_{q}$ method can be expressed as follows:

$$
\left[\begin{array}{c}
i_{d} \\
i_{q} \\
i_{0}
\end{array}\right]=\frac{1}{v_{\alpha \beta}}\left[\begin{array}{ccc}
v_{\alpha} & v_{\beta} & 0 \\
-v_{\beta} & v_{\alpha} & 0 \\
0 & 0 & v_{\alpha \beta}
\end{array}\right]\left[\begin{array}{c}
i_{L \alpha} \\
i_{L \beta} \\
i_{L 0}
\end{array}\right] .
$$

In this strategy, the source must deliver the constant term of the direct-axis component of the load (for harmonic compensation [9] and power factor correction). The reference source current can be calculated as follows:

$$
\begin{gathered}
i_{s d}=\overline{i_{L d}} ; \quad i_{s q}=i_{s o}=0 \\
i_{L d}=\frac{v_{\alpha} i_{L \alpha}+v_{\beta} i_{L \beta}}{v_{\alpha \beta}}=\frac{P_{L \alpha \beta}}{\sqrt{v_{\alpha}^{2}+v_{\beta}^{2}}} .
\end{gathered}
$$

The dc component of the above equation will be:

$$
\overline{i_{L d}}=\left(\frac{P_{L \alpha \beta}}{v_{\alpha \beta}}\right)_{d c}=\left(\frac{P_{L \alpha \beta}}{\sqrt{v_{\alpha}^{2}+v_{\beta}^{2}}}\right)_{d c} .
$$

Where the subscript "dc" means the average value of the expression within the parentheses.

Since the reference source current must to be in phase with the voltage at the PCC (and have no zero-sequence component), it is calculated (in the $\alpha-\beta-0$ coordinates) by multiplying the above equation by a unit vector in the direction 


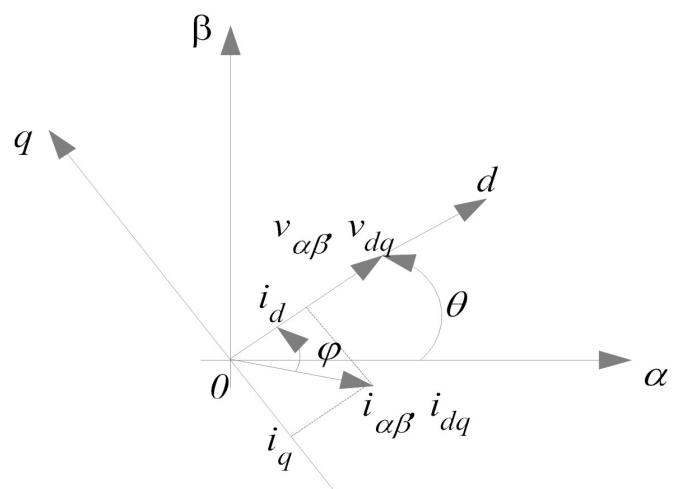

Fig. 4. Instantaneous voltage and current vectors.

of the PCC voltage space vector (excluding the zero-sequence component):

$$
\begin{aligned}
& i_{\text {sref }}=\overline{i_{L d}} \frac{1}{v_{\alpha \beta}}\left[\begin{array}{l}
v_{\alpha} \\
v_{\beta} \\
0
\end{array}\right] \\
& {\left[\begin{array}{c}
i_{\text {saref }} \\
i_{\text {s及ref }} \\
i_{\text {soref }}
\end{array}\right]=\left(\frac{P_{L \alpha \beta}}{v_{\alpha \beta}}\right)_{d c} \frac{1}{v_{\alpha \beta}}\left[\begin{array}{l}
v_{\alpha} \\
v_{\beta} \\
0
\end{array}\right]} \\
& {\left[\begin{array}{c}
i_{\text {saref }} \\
i_{s \beta r e f} \\
i_{s 0 r e f}
\end{array}\right]=\left(\frac{P_{L \alpha \beta}}{\sqrt{v_{\alpha}^{2}+v_{\beta}^{2}}}\right)_{d c} \frac{1}{\sqrt{v_{\alpha}^{2}+v_{\beta}^{2}}}\left[\begin{array}{l}
v_{\alpha} \\
v_{\beta} \\
0
\end{array}\right] .}
\end{aligned}
$$

The reference signals thus obtained are compared with the actual compensating filter currents in a hysteresis comparator, where the actual current is forced to follow the reference and it provides instantaneous compensation by the APF [9]. The main advantages of this are its easy implementation and its quick response to fast current transitions. This consequently provides switching signals to trigger the IGBTs inside the inverter. Ultimately, the filter provides the necessary compensation for the harmonics in the source current and the reactive power unbalance in the system. Fig. 3 shows the voltage and current vectors in the stationary and the rotating reference frames. The transformation angle ' $\theta$ ' is sensible for all voltage harmonics and unbalanced voltages. As a result $d \theta / d t$ may not be constant.

One of the advantages of this method is that the angle $\theta$ is calculated directly from the main voltages, making this method frequency independent. Consequently the synchronizing problems with the unbalanced and distorted conditions of the main voltages are also avoided. Thus with $i_{d}-i_{q}$ a large frequency operating limit can be achieved. This is accomplished essentially by the cut-off frequency of the voltage source inverter (VSI). After the load currents $i_{d}$ and $i_{q}$ are obtained from the park transformation, they are allowed to pass through a high pass filter to eliminate the dc components in the nonlinear load currents. The filters used in the circuit are the Butterworth type and to reduce the influence of the high pass filter an alternative high pass filter (AHPF) can be used in the circuit. This can be obtained through a low pass filter (LPF) of the same order and cut-off frequency simply by calculating the difference between the input signal and the filtered one, which is clearly shown in

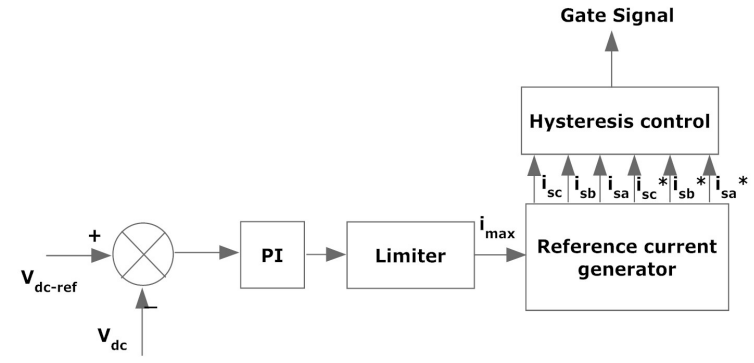

Fig. 5. Conventional PI Controller

Fig. 7. The Butterworth filters used in the harmonic injecting circuit have a cut-off frequency equal to one half of the main frequency $\left(f_{c}=f / 2\right)$. With a small phase shift in harmonics a sufficiently high transient response can be obtained.

\section{CONSTRUCTION OF THE PI CONTROLleR}

Fig. 5 shows the internal structure of the control circuit. The control scheme consists of a PI controller, a limiter, and a three phase sine wave generator for reference current and switching signal generation. The peak value of the reference currents is estimated by regulating the DC link voltage. The actual capacitor voltage is compared with a set reference value [10].

The error signal is then processed through a PI controller, which contributes to the zero steady error in tracking the reference current signal. The output of the PI controller is considered as the peak value of the supply current $\left(I_{\max }\right)$, which is composed of two components: (a) the fundamental active power component of the load current, and (b) the loss component of the APF; to maintain the average capacitor voltage at a constant value. The peak value of the current $\left(I_{\max }\right)$ so obtained, is multiplied by the unit sine vectors in phase with the respective source voltages to obtain the reference compensating currents. These estimated reference currents $\left(\mathrm{I}_{s a} a^{*}, \mathrm{I}_{s b} *\right.$, and $\left.\mathrm{I}_{s c}{ }^{*}\right)$ and the sensed actual currents ( I $s a, \mathrm{I} s b$, and Isc) are compared to a hysteresis band, which gives the error signal for the modulation technique. This error signal decides the operation of the converter switches. In this current control circuit configuration, the source/supply currents $I_{s a b c}$ are made to follow the sinusoidal reference current $I_{a b c}$, within a fixed hysteretic band. The width of the hysteresis window determines the source current pattern, its harmonic spectrum and the switching frequency of the devices.

The DC link capacitor voltage [11] is kept constant throughout the operating range of the converter. In this scheme, each phase of the converter is controlled independently. To increase the current of a particular phase, the lower switch of the converter associated with that particular phase is turned on. To decrease the current the upper switch of the respective converter phase is turned on. With this the potential and the feasibility of the PI controller [12] can be realized.

\section{CONSTRUCtion OF FuZzy CONTROLler}

Fig. 6 shows the internal structure of the control circuit. The control scheme consists of a Fuzzy controller [13], a limiter, and a three phase sine wave generator for the generation of 


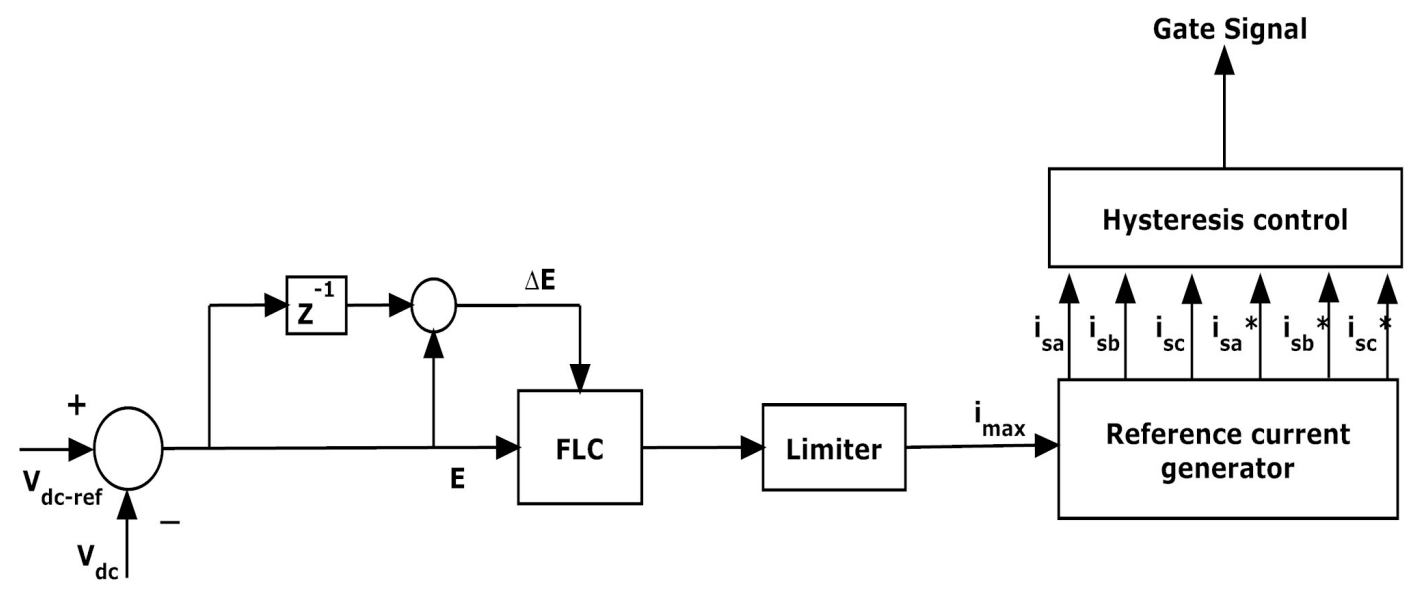

Fig. 6. Proposed Fuzzy Controller.

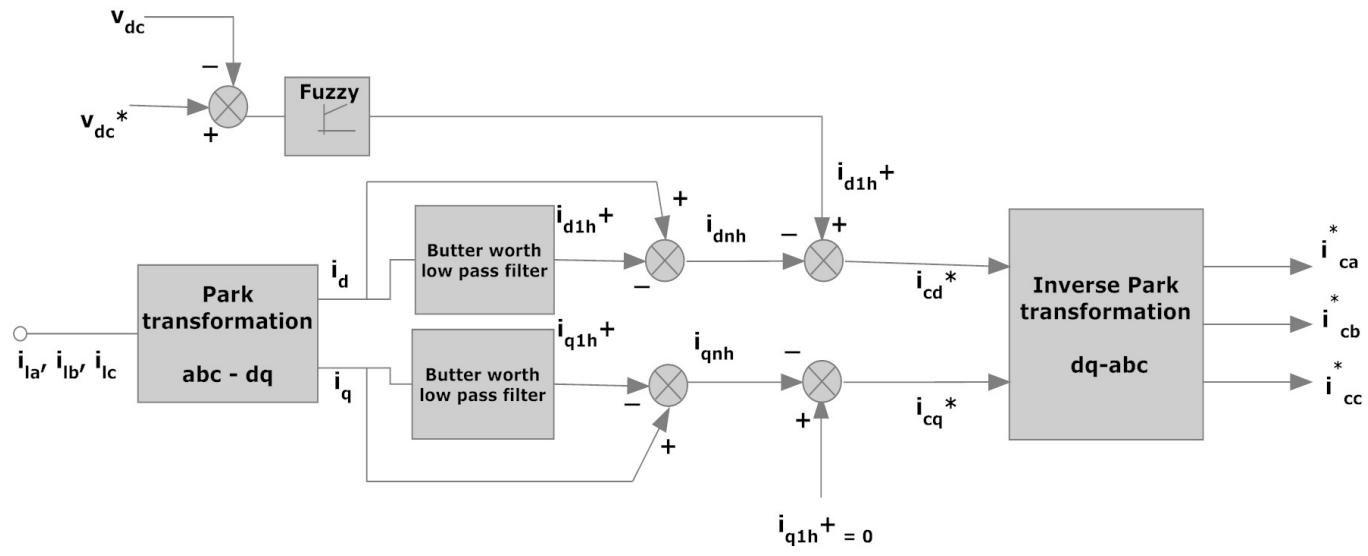

Fig. 7. Reference current extraction with $\mathrm{i}_{d}-\mathrm{i}_{q}$ method with Fuzzy controller.

reference currents and switching signals. The peak value of the reference current is estimated by regulating the DC link voltage. The actual capacitor voltage is compared with a set reference value. The error signal is then processed through a Fuzzy controller, which contributes to the zero steady error in tracking the reference current signal.

A fuzzy controller converts a linguistic control strategy into an automatic control strategy, and fuzzy rules are constructed either by expert experience or with a knowledge database [14]. Firstly, the input Error ' $E$ ' and the change in Error ' $\triangle E$ ' have been placed with the angular velocity to be used as the input variables of the fuzzy logic controller. Then the output variable of the fuzzy logic controller is presented by the control Current $\mathrm{I}_{\max }$. To convert these numerical variables into linguistic variables, the following seven fuzzy levels or sets are chosen: NB (negative big), NM (negative medium), NS (negative small), ZE (zero), PS (positive small), PM (positive medium), and PB (positive big), as can be seen in Figure 8.

Rule Base: The elements of this rule base table are determined based on the theory that in the transient state, large errors need coarse control, which requires coarse input/output variables, while in the steady state, small errors need fine control, which requires fine input/output variables. Based on this, the elements of the rule table are obtained as shown in
Table I, with ' $\mathrm{E}$ ' and ' $\triangle \mathrm{E}$ ' as inputs.

\section{System PeRformance}

Fig. 9 and Fig. 10 illustrate the performance of the shunt active power filter under different main voltages. As the load is highly inductive, the current draw by the load is integrated with rich harmonics.

\section{A. Numerical Simulations}

A simulation is carried out with only an AHPF (alternative high pass filter) of the $2^{\text {nd }}$ order with a cut-off frequency of $f_{c}=f_{c} / 2$. It is also assumed that currents are independent of the main voltages and that there is no ripple on the rectifier dc current. The active power filter performance is analyzed under several different main voltage conditions. In addition the simulation is also extended to different kinds of filters like a HPF (high pass filter) of the $2^{\text {nd }}$ order, an AHPF of the $4^{\text {th }}$ order and a HPF of the $4^{\text {th }}$ order. In all of these, the alternative high pass filter shows good performance and it is easy to obtain with a LPF (low pass filter) of the same order and cut-off frequency, simply by using the difference between the input and the filter signal, which is shown in Fig.7. The graphs shown in Fig.11 and Fig.12 summarize the total performance of the shunt active filter with different filters. 


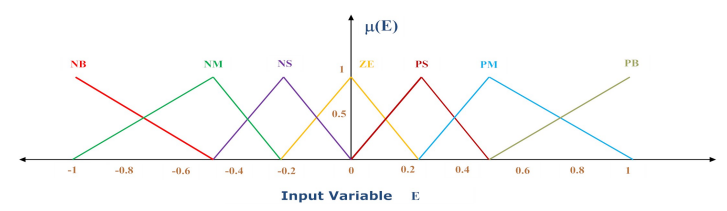

(a)

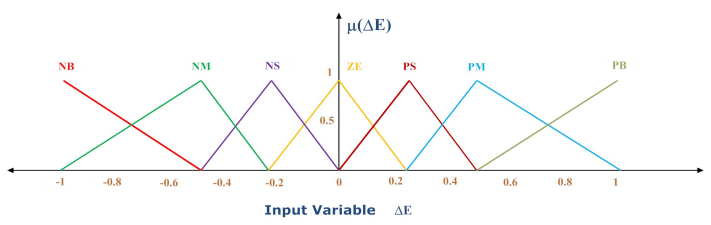

(b)

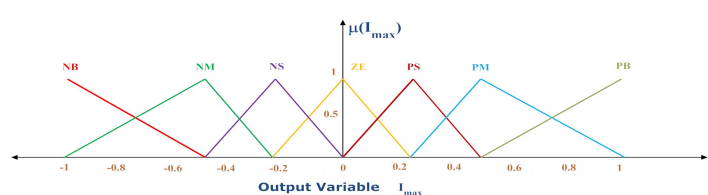

(c)

Fig. 8. (a) Input Variable Error 'E' Membership Function. (b) Input Change in Error Normalized MF. (c) Output Imax Normalized MF.

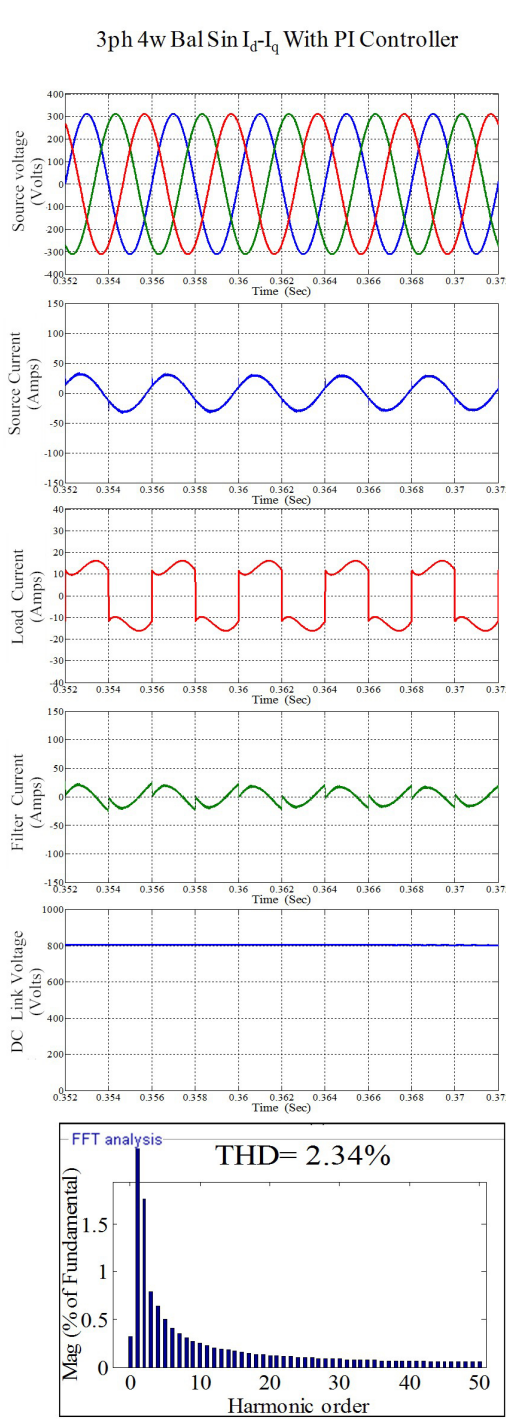

(a)

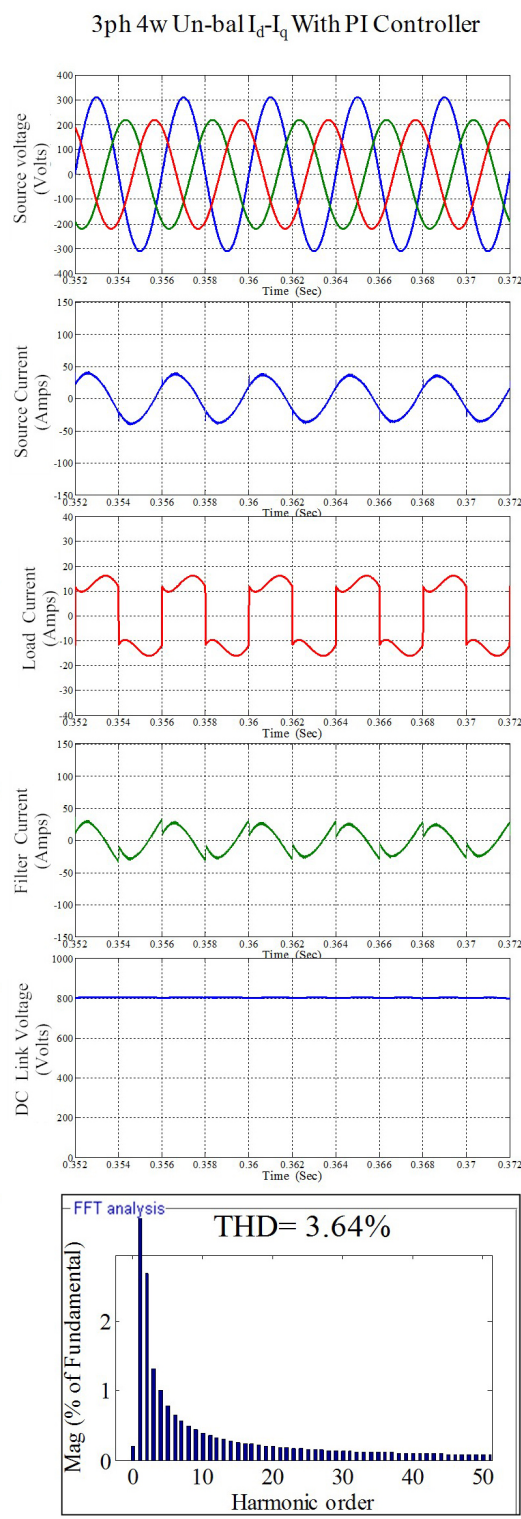

(b)

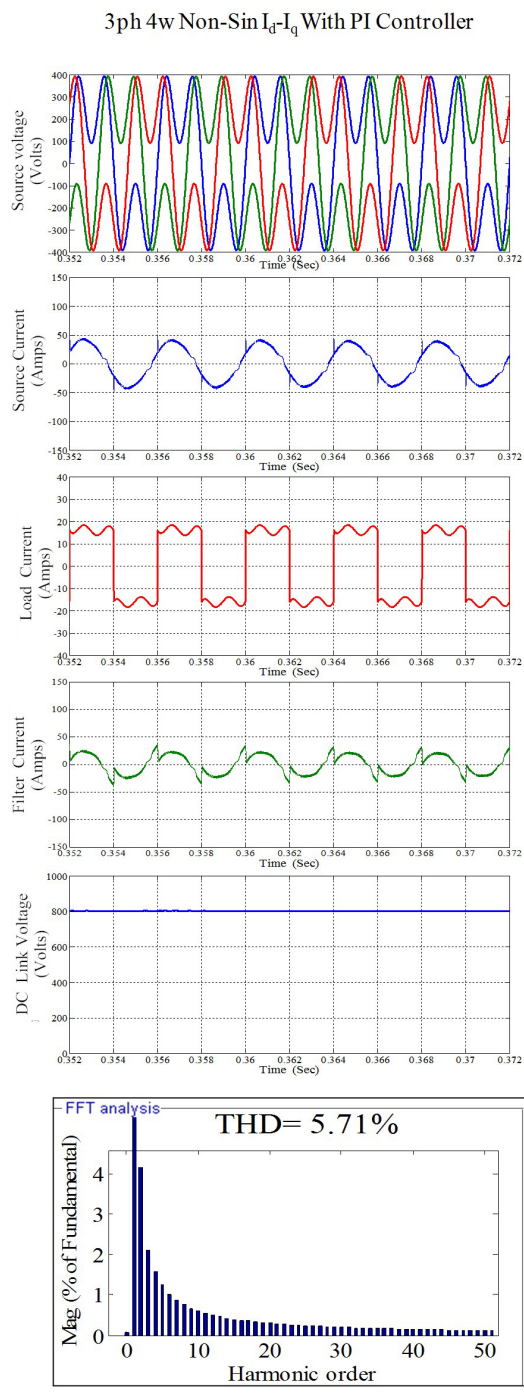

(c)

Fig. 9. 3ph 4wire Shunt ative filter using $\mathrm{I}_{d}-\mathrm{I}_{q}$ Control Strategy response with PI controller Under (a) Balanced Sinusoidal. (b)Un-balanced Sinusoidal. (c) Balanced Non-Sinusoidal. 


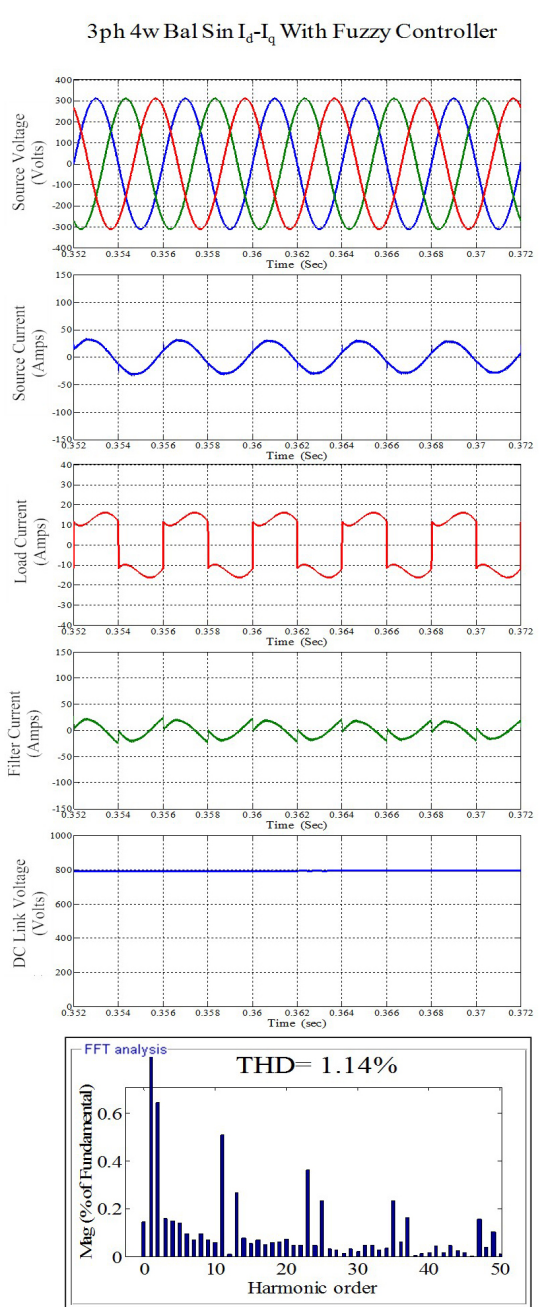

(a)

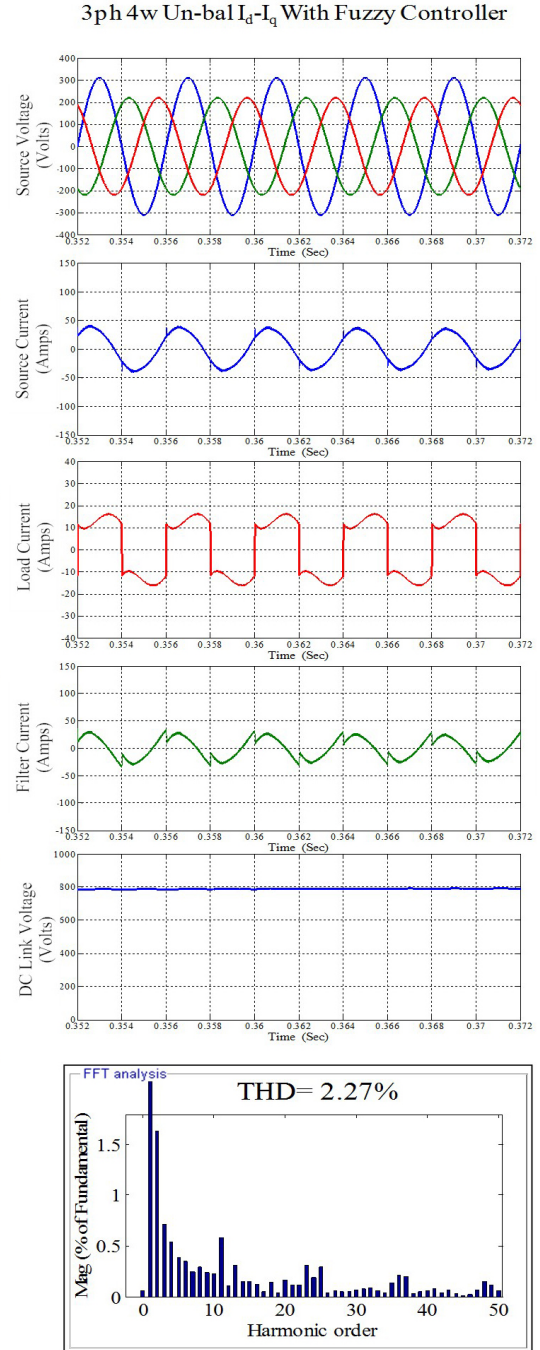

(b)

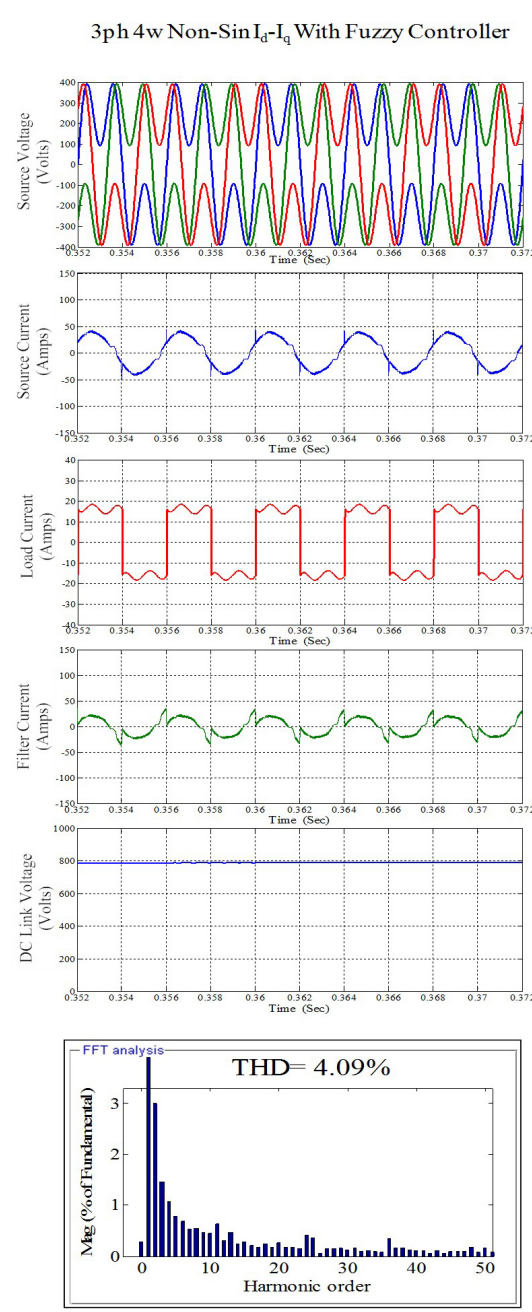

(c)

Fig. 10. 3ph 4wire Shunt ative filter using $\mathrm{I}_{d}-\mathrm{I}_{q}$ Control Strategy response with Fuzzy controller Under (a) Balanced Sinusoidal. (b)Un-balanced Sinusoidal. (c) Balanced Non-Sinusoidal.

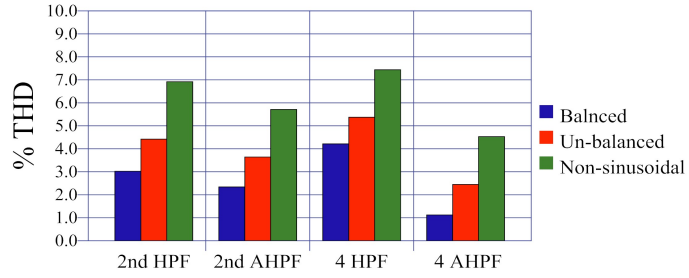

Fig. 11. THD for $\mathrm{i}_{d}-\mathrm{i}_{q}$ method with PI controller.

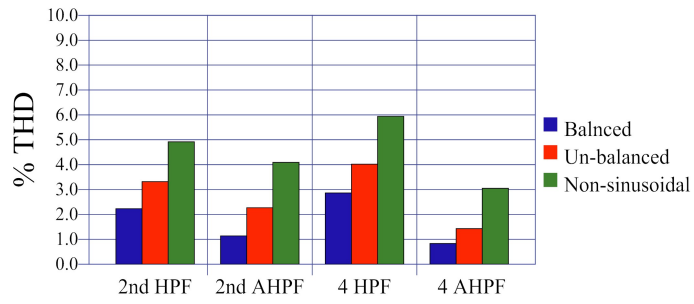

Fig. 12. THD for $\mathrm{i}_{d}-\mathrm{i}_{q}$ method with Fuzzy controller.

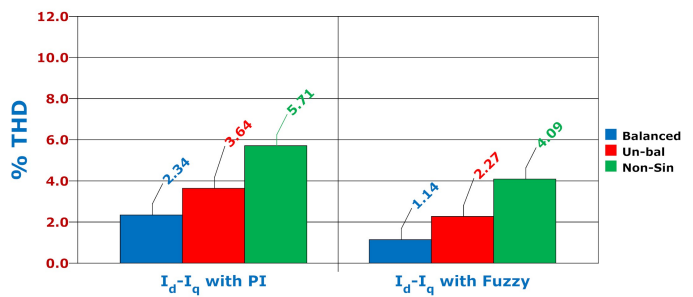

Fig. 13. THD of Sinusoidal current for $\mathrm{I}_{d}-\mathrm{I}_{q}$ method with PI and Fuzzy controllers.

The results presented confirm the superior performance of the Fuzzy controller. However, the performance of the shunt active filters with both controllers under sinusoidal conditions are the same. Generally speaking among all of the filters, the HPF gives the best filtering action under any voltage conditions.

Initially the system performance is analyzed under balanced sinusoidal conditions, during which the PI and Fuzzy controllers are good enough at suppressing the harmonics and THD to about $2.34 \%$ and $1.14 \%$. However, under un- 
TABLE I

RULE BASE

\begin{tabular}{|c|c|c|c|c|c|c|c|}
\hline \multicolumn{1}{|c|}{$\Delta \mathrm{E}$} & NB & NM & NS & $Z$ & PS & PM & PB \\
\hline NB & NB & NB & NB & NB & NM & NS & $Z$ \\
\hline NM & NB & NB & NB & NM & NS & $Z$ & PS \\
\hline NS & NB & NB & NM & NS & Z & PS & PM \\
\hline PS & NB & NM & NS & Z & PS & PM & PB \\
\hline PM & NS & Z & PS & PM & PB & PB & PB \\
\hline PB & $Z$ & PS & PM & PB & PB & PB & PB \\
\hline
\end{tabular}

TABLE II

SYSTEM PARAMETERS

\begin{tabular}{|c|c|}
\hline Parameter & Value \\
\hline Supply Voltage & $\mathrm{V}_{\mathrm{s}}=311.12 \mathrm{~V}$ \\
\hline Source Resistance & $\mathrm{R}_{\mathrm{s}}=\mathbf{0 . 1} \Omega$ \\
\hline Source Inductance & $\mathrm{L}_{\mathrm{s}}=1 \mathrm{mH}$ \\
\hline Filter Phase-branch Resistance & $\mathrm{R}_{\mathrm{f}}=\mathbf{0 . 0 1 \Omega}$ \\
\hline Filter Phase-branch Inductance & $\mathrm{L}_{\mathrm{f}}=\mathbf{0 . 1 \mathrm { mH }}$ \\
\hline DC Link Capacitance & $\mathrm{C}_{\mathrm{dc}}=3000 \mu \mathrm{f}$ \\
\hline DC Link Voltage & $\mathrm{V}_{\mathrm{dc}}=800 \mathrm{~V}$ \\
\hline Hysterisis band & $\pm 0.2 \mathrm{~A}$ \\
\hline Load & Diode rectifier \\
\hline Load Resistance & Snubber Resistance $\mathrm{R}_{\mathrm{sn}}=500 \Omega$ \\
\hline Load Inductance & Snubber Capacitance $\mathrm{L}_{\mathrm{sn}}=250 \mathrm{e}-9 \mathrm{f}$ \\
\hline & $\mathrm{R}_{\mathrm{L}}=15 \Omega$ \\
\hline
\end{tabular}

balanced and non-sinusoidal conditions the fuzzy controller shows superior performance over the PI controller. With the PI controller the THD are $3.64 \%$ and $5.71 \%$, while with the fuzzy controller they are about $2.27 \%$ and $4.09 \%$. It can be seen that the PI controller fails to respond quickly because of its non-linear nature in the system. However, the fuzzy controller shows outstanding performance under any voltage conditions.

Frankly, the fuzzy controller is the most sensitive of all the controllers. However, it also has some drawbacks like redundancy and iteration problems. Therefore, the membership function must be chosen on the bases system complexity. Extensive simulations were carried out to validate both of the controllers. With all of the different combinations of $I_{d^{-}}$ $I_{q}$ strategy and fuzzy controller; there is the possibility of building a novel shunt active filter for 3-phase 4-wire systems.

\section{CONCLUSION}

In the present paper two controllers are developed and verified for three phase four wire systems. Even though both of the presented controllers are capable of compensating current harmonics in 3 phase 4-wire systems, it can be seen that the Fuzzy Logic controller has a better dynamic performance than the conventional PI controller. PWM pattern generation based on carrier-less hysteresis current control is used for quick response. Additionally, in contrast to the different control strategies; the $i_{d}-i_{q}$ method is used for obtaining the reference currents in the system. This is due to the fact that the angle ' $\theta$ ' is calculated directly from the main voltages which enables an operation which is frequency independent. As a result, this technique avoids large number of synchronization problems. It can also be seen that the DC voltage regulation system is a stable and steady-state error free system. Thus with fuzzy logic and the $(i d-i q)$ approach, a novel shunt active filter can be developed. Simulation results are presented to validate the performance of the shunt active filter.

\section{REFERENCES}

[1] H. Akagi "New trends in active filters for power conditioning," IEEE Trans. Ind. Appl., Vol. 32, No. 6, pp. 1312-1322, Nov./Dec.1996.

[2] F. Z. Peng, G. W. Ott Jr., D. J. Adams, "Harmonic and reactive power compensation based on the generalized instantaneous reactive power theory for three-phase four-wire systems" IEEE Trans. Power Electron., Vol. 13, No. 5, pp. 1174-1181, Nov. 1998.

[3] V. Soares, P. Verdelho, and G. Marques, "Active power filter control circuit based on the instantaneous active and reactive current $i_{d}-i_{q}$ method," IEEE Power Electronics Specialists Conference, Vol. 2, pp. 1096-1101, 1997.

[4] M Suresh, A. K. Panda, S. S. Patnaik, and S. Yellasiri, "Comparison of two compensation control strategies for shunt active power filter in three-phase four-wire system," in Proc. IEEE PES Innovative Smart Grid Technologies, pp. 1-6, 2011

[5] H. Akagi, Y. kanazawa, and A. Nabae "Instantaneous reactive power compensators comprisingSwitching devices without energy storage components," IEEE Trans. Ind. Appl., Vol. Ia-20, No. 3, pp 625-630, May/Jun. 1984.

[6] M. Suresh, A. K. Panda, Y. Suresh, "Fuzzy controller based 3phase 4wire shunt active filter for mitigation of current harmonics with combined p-q and id-iq control strategies," Journal of Energy and Power Engineering, Vol. 3, No.1, pp. 43-52, Feb. 2011.

[7] M. I. M Montero, E. R. Cadaval, and F. B. Gonzalez, "Comparison of control strategies for shunt active power filters in three-phase four-wire systems," IEEE Trans. Power Electron., Vol. 22, No. 1, Jan. 2007.

[8] H. Akagi, E. H. Watanabe, and M. Aredes, Instantaneous Power Theory and Applications to Power Conditioning, New Jersey, IEEE Press/WileyInter-science, 2007.

[9] M. Aredes, J. Hafner, and K. Heumann, "Three-phase four-wire shuntactive filter control strategies," IEEE Trans. Power Electron. Vol. 12, No. 2, pp. 311-318, Mar. 1997.

[10] P.Rodriguez, J. I. Candela, A. Luna, and L. Asiminoaei, "Current harmonics cancellation in three-phase four-wire systems by using a fourbranch star filtering topology," IEEE Trans. Power Electron. Vol. 24, No. 8, pp. 1939-1950, Aug. 2009.

[11] P. Kirawanich and R. M. O'Connell, "Fuzzy logic control of an activepower line conditioner," IEEE Trans. Power Electron. Vol. 19, No. 6, pp. 1574-1585, Nov. 2004.

[12] S. Mikkili and A. K. Panda, "APF for mitigation of current harmonics with p-q and id-iq controlstrategies using pi controller," Journal of Trends in Electrical Engineering, Vol. 1, No. 1, pp. 1-11, May 2011.

[13] S. K. Jain, P. Agrawal, and H. O. Gupta, "Fuzzy logic controlled shunt active power filter for power quality improvement," IEEE Proceedings Electric Power Applications, Vol.1 49, No. 5, pp. 317-328, Sep. 2002.

[14] S. Mikkili and A. K. Panda, "RTDS Hardware implementation and Simulation of 3-ph 4-wire SHAF for Mitigation of Current Harmonics with p-q and Id-Iq Control strategies using Fuzzy Logic Controller," International Journal of Emerging Electric Power Systems, bepress, Vol. 12, No. 5, Article 5, 2011. 


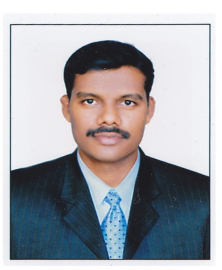

Suresh Mikkili was born in Bapatla, Andhra Pradesh, India, on $5^{\text {th }}$ August 1985. He received his B.Tech. in Electrical and Electronics Engineering from the Jawaharlal Nehru Technological University (JNTU), Hyderabad, India, in May 2006, and his M.Tech. in Electrical Engineering from the National Institute of Technology (NIT), Rourkela, India, in May 2008. He has worked as a Assistant Professor of Electrical Engineering at distinguished engineering colleges from June 2008 to July 2010 . He is currently pursuing his Ph.D. in Electrical Engineering at NIT, Rourkela, India. His current research includes include power quality improvement issues, active filters, and the application of soft computing techniques.

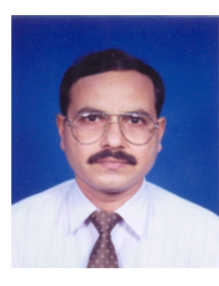

Anup Kumar Panda received his B.Tech. in Electrical Engineering from Sambalpur University, India, in 1987. He received his M.Tech. in Power Electronics and Drives from the Indian Institute of Technology, Kharagpur, India, in 1993, and his Ph.D. from Utkal University, in 2001. He joined the faculty at the Indira Gandhi Institute of Technology (IGIT), Sarang, India, in 1990. He served there for eleven years and then joined the National Institute of Technology (NIT), Rourkela, in January 2001, as an Assistant Professor. He is currently working there as a Professor in the Department of Electrical Engineering. He has published over fifty articles in journals and conferences and has completed two MHRD projects and one NaMPET project. He has guided three Ph.D. scholars and is currently guiding four more scholars in the area of Power Electronics and Drives. His current research interest include the analysis and design of high frequency power conversion circuits, power factor correction circuits, power quality improvement in power systems and electric drives, and the applications of soft computing techniques. 